\title{
Association between serum insulin like growth factor-1 (IGF-1) and insulin-like growth factor-binding protein-3 levels and chronic kidney disease in diabetic patients
}

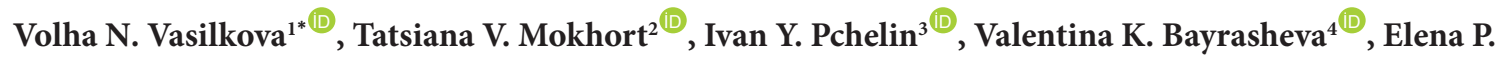 \\ Naumenko ${ }^{5}$, Ludmila E. Korotaeva ${ }^{5}$, Natallia A. Filiptsova ${ }^{5}$ \\ ${ }^{1}$ Department of Internal Medicine №1, Gomel State Medical University, Gomel, Belarus \\ ${ }^{2}$ Endocrinology Department, Belarusian State Medical University, Minsk, Belarus \\ ${ }^{3}$ Department of Faculty Therapy, Saint Petersburg State University, Saint Petersburg, Russia \\ ${ }^{4}$ Institute of Endocrinology, Almazov National Medical Research Centre, Saint Petersburg, Russia \\ ${ }^{5}$ Laboratory Department, Republican Research Centre for Radiation Medicine and Human Ecology, Gomel, Belarus
}

\section{A R T I C L E I N F 0}

Article Type:

Original

Article History:

Received: 7 December 2019

Accepted: 27 January 2020

Published online: 10 March 2020

\section{Keywords:}

Insulin like growth factor-1, Insulin-like growth factorbinding protein-3, Diabetes mellitus, Chronic kidney disease, Diabetic nephropathy, Glomerular filtration rate

\begin{abstract}
A B S T R A C T
Introduction: Insulin-like growth factor-1 (IGF-1) is a potent mitogen for glomerular mesangial cells which can stimulate cell migration and the production of fibronectin, proteoglycan, and type IV collagen, thereby promoting the development of the chronic kidney disease (CKD) in patients with diabetes.

Objectives: The aim of the study was to assess the associations between serum levels of IGF-1 and insulin-like growth factor-binding protein-3 (IGFBP-3) and CKD in diabetic patients.

Patients and Methods: We investigated 102 Belarusian men and women with diabetes type 2 aged $56.67 \pm 0.81$ years. Control group included 68 healthy people the same age. We estimated GFR with the use of the CKD-EPI creatinine-cystatin C equation to determine eGFRcr_cys. Serum total IGF1 and IGFBP-3 levels were measured using immunoradiometric assay (IRMA) (Beckman Coulter, Czech Republic s.r.o.).

Results: Patients with diabetes had significantly lower level of IGF-1 than controls. However, IGFBP-3 levels were similar in the two groups. Diabetic patients with CKD had significantly higher levels of IGF-1 and IGFBP- 3 than diabetic patients without CKD $(P=0.0031)$. However, according to multivariate analysis, only IGF- 1 and cystatin $C$ were associated with renal impairment. In detail, the odds of having eGFR $<60 \mathrm{~mL} / \mathrm{min} / 1.73 \mathrm{~m}^{2}$ increased with rising IGF-1 levels (OR: 1.025, [CI 1.002-1.048]).

Conclusion: Our study revealed that higher serum IGF-1 levels were positively associated with CKD in patients with diabetes. We suggest that IGF-1 might be a predictor of CKD in patients with diabetes. Further research is necessary to confirm the observed this association and to detect the causal relations.
\end{abstract}

\section{Implication for health policy/practice/research/medical education:}

Insulin-like growth factor-1 (IGF-1) is a potent mitogen for glomerular mesangial cells, and consequently, it can promote the development of the chronic kidney disease (CKD) in patients with diabetes. However, data on the interconnections between IGF1 and CKD in different clinical groups are limited and contradictory. In this study we examined patients with type 2 diabetes and different degrees of renal dysfunction and demonstrated an independent association between the levels of glomerular filtration rate (GFR) and IGF-1, as well as the absence of an independent association between the levels of GFR and insulin-like growth factor-binding protein-3.

Please cite this paper as: Vasilkova VN, Mokhort TV, Pchelin IY, Bayrasheva VK, Naumenko EP, Korotaeva LE, et al. Association between serum insulin like growth factor-1 (IGF-1) and insulin-like growth factor-binding protein-3 levels and chronic kidney disease in diabetic patients. J Renal Inj Prev. 2021; 10(1): e05. doi: 10.34172/jrip.2021.05.

\section{Introduction}

Diabetes mellitus is the leading cause of chronic kidney disease $(\mathrm{CKD})$ in developed countries. It is recognized as one of the major risk factors for adverse outcomes, including cardiovascular events, end stage renal disease, and death (1-3). In patients with type 1 diabetes (T1DM), screening for nephropathy should start five years after diagnosis of diabetes because it usually takes about 5 
years for this complication to develop. In patients with type 2 diabetes (T2DM), screenings should begin at initial diagnosis since the exact onset of diabetes is unknown in most cases (4). During the last decades, serum creatinine concentration has become the most commonly used marker for estimation of glomerular filtration rate (GFR). However, recently, serum cystatin $\mathrm{C}$ has been proposed as a new endogenous marker of kidney function which is less influenced by muscle mass, sex and age (5). Some studies have demonstrated that serum cystatin $\mathrm{C}$ concentration is a better indicator of GFR in patients with diabetes and a better predictor of mortality and adverse cardiovascular events than serum creatinine $(6,7)$.

Kidney function estimation is commonly made using serum creatinine, serum cystatin $\mathrm{C}$ and urine analysis, since accumulating evidence has shown that these markers are not optimal for detection of kidney disease at early stages $(8,9)$.

It is known that insulin-like growth factor-1 (IGF1) is a potent mitogen for glomerular mesangial cells which can stimulate cell migration and the production of fibronectin, proteoglycan, laminin, and type IV collagen, thereby promoting the development of CKD in patients with diabetes (10). It has been shown that patients with diabetes and microalbuminuria present with severe alterations in the growth hormone-insulin-like growth factor-insulin-like growth factor binding protein (GHIGF-IGFBP) system, with increased IGF-1 renal levels and IGF-1 binding protein 3 (IGFBP-3) protease activity, increased excretion of bioactive GH, IGF-1, and IGFBP-3, with a decrease in circulating intact IGFBP-3 levels. At the same time data regarding levels of IGF-1 in diabetic patients have yielded conflicting results. Decreased serum IGF-1 levels have been noted in diabetic subjects with reduced kidney function (11). However, increased IGF-1 and IGFBP-3 levels have been found in adult patients with decreased estimated GFR (12).

\section{Objectives}

The aim of this study was to assess the associations between serum levels of IGF-1 and insulin-like growth factor-binding protein-3 (IGFBP-3) and CKD in diabetic patients.

\section{Patients and Methods \\ Study participants}

We investigated 102 Belarusian men and women with T2DM who consecutively referred to the Republican Research Centre for Radiation Medicine and Human Ecology (Gomel, Republic of Belarus) institution. The inclusion criteria were presence of T2DM, age between 20 and 80 years, and body mass index (BMI) between 18.5 and $40.0 \mathrm{~kg} / \mathrm{m}^{2}$. All patients were treated with diet and oral antidiabetic drugs. Patients with signs of end stage renal failure, overt infection, pituitary adenomas, severe liver inflammation, treated with glucocorticoids were excluded. Control group included 68 healthy people the same age. Demographic parameters were evaluated, height and weight were measured, and BMI was calculated.

\section{Biochemical measurements}

Fasting blood samples were collected from each patient in the morning after overnight fasting. Serum was separated by centrifugation at $3000 \mathrm{rpm}$ for 15 minutes within 2hours after sample collection. All the laboratory tests were completed within 8 hours.

Plasma total cholesterol (TC), high-density lipoprotein cholesterol (HDL-cholesterol), and triglyceride (TG) concentrations were assessed using standard enzymatic methods, and low-density lipoprotein cholesterol (LDLcholesterol) and very low-density lipoprotein cholesterol (VLDL-cholesterol) were calculated by the Friedewald equation. Hemoglobin $\mathrm{A}_{1 \mathrm{c}}\left(\mathrm{HbA}_{1 \mathrm{c}}\right)$ was assayed using high-performance liquid chromatography.

Kidney function was estimated by serum creatinine (Cr) and cystatin C. All assays were performed in frozen serum specimens that were stored at $-70^{\circ} \mathrm{C}$. Serum $\mathrm{Cr}$ was analyzed using Jaffe method and was traceable to the international standardization with isotope dilution mass spectrometry. Serum cystatin $\mathrm{C}$ was assessed by immunoturbidimetric assay (inter-assay and intraassay coefficients of variation were $<3.6 \%$ and $<2.7 \%$, respectively).

We estimated GFR with the use of the Chronic Kidney Disease Epidemiology Collaboration (CKD-EPI) creatinine-cystatin $C$ equation to determine eGFRcr cys $(\mathrm{eGFR}=135 \times \min (\mathrm{SCr} / \kappa, 1) \alpha \times \max (\mathrm{SCr} / \kappa, 1)-$ $0.601 \times \min ($ Scys/0.8, 1) $-0.375 \times \max ($ Scys/0.8, 1) - $0.711 \times 0.995$ Age $\times 0.969$ [if female]) (13). Urinary albumin creatinine ratio (UACR) was determined from urinary creatinine and albumin measurements from spot midstream urine.

Serum total IGF-1 and IGFBP-3 levels were measured using immunoradiometric assay (IRMA) (Beckman Coulter, Czech Republic s.r.o.). Accurate evaluation of serum levels of IGF-1 and IGFBP-3 was performed in one assay. The sensitivity of IGF-1 assay was $5.0 \mathrm{ng} / \mathrm{mL}$, intra-assay $\mathrm{CV}$ was $8.6 \%$, and the inter-assay CV was $10.2 \%$. The sensitivities of IGFBP-3 assay, the intra-assay $\mathrm{CV}$ and the inter-assay CV were $1 \mathrm{ng} / \mathrm{mL}, 1.1 \%$, and $1.8 \%$, respectively.

\section{Ethical issues}

Human rights were respected in accordance with the Helsinki Declaration 1975, as revised in 1983. Informed consent was obtained from all patients to conduct this study. The ethical committee of The Republican Research Centre for Radiation Medicine and Human Ecology (Registration Number 134 M 6542) approved this study. This study was supported by the Belarusian Foundation 
for Basic Research (research project \# M17PM-113; 01.06.2017) and Russian Foundation for Basic Research (Research project \#17-54-04080). The informed consent was also obtained from the patients for the publication of this investigation.

\section{Statistical analysis}

Data are presented as mean \pm standard deviation or median (25th-75th percentile) where appropriate. Spearman rank correlation analysis was performed to evaluate associations of IGF-1 and IGFBP-3 with other existing parameters. For bivariate comparisons the KruskalWallis test was used. Analysis of variance (ANOVA) with adjustment for age and $\mathrm{HbA1c}$ was performed to assess the associations between serum IGF-1 or IGFBP-3 and eGFRcr_cys. Multivariate linear regression analysis was also performed to evaluate IGF-1 or IGFBP-3 as potential independent predictors of CKD. $P$ value $<0.05$ was considered statistically significant. Statistical processing of the obtained data was performed using smStata $\mathrm{v} 14.2$ software (StataCorp, Texas, USA).

\section{Results}

Characteristics of the study participants are shown in Table 1. Mean age of patients with diabetes was $59.84 \pm 14.03$ years, duration of diabetes was $12.88 \pm 7.61$ years, and HbAlc was $7.82 \pm 1.69 \%$. Mean creatinine, cystatin C, eGFRcr_cys, UACR were $87.82 \pm 56.93$ umol/l, $0.94 \pm 0.54 \mathrm{mg} / \mathrm{L}, \quad 76.78 \pm 25.41 \mathrm{ml} / \mathrm{min} / 1.73 \mathrm{~m}^{2}$ and $7.83 \pm 12.50 \mathrm{mg} / \mathrm{g}$, respectively. There were significant differences in age, $\mathrm{HbA1c}$, systolic and diastolic blood pressure (BP), triglycerides, VLDL-cholesterol, HDL- cholesterol levels, creatinine, cystatin C, eGFRcr_cys and UACR between the main and the control groups. Patients with diabetes had a significantly lower level of IGF-1 than controls (98.6 (74.1-163.9) ng/mL versus 185.1 (133-287) ng/mL, $P=0.0127$, respectively). However, IGFBP-3 levels were similar in the two groups $(2438(1639-3004) \mathrm{ng} / \mathrm{mL}$ versus 2511 (1008-3099) $\mathrm{ng} / \mathrm{mL}, P=0.999)$.

According to the results of univariate linear regression analysis, IGF-1 level was significantly correlated with age $(\mathrm{r}=-0.36, P=0.006)$, cystatin $\mathrm{C}(\mathrm{r}=0.61, P=0.0005)$, serum creatinine $(\mathrm{r}=0.40, P=0.03)$ and eGFRcr_cys $(\mathrm{r}=-0.35, P=0.0042)$, since IGFBP-3 had also similar interrelationships with the same variables. Meanwhile, both IGF-1 and IGFBP-3 were not significantly correlated with age, duration of diabetes, BMI, HbAlc, TC, triglycerides, HDL-C, and LDL-C (Table 2).

We divided the patients into two groups according to presence of CKD with GFR reduction (eGFRcr_cys $<60$ $\mathrm{mL} / \mathrm{min} / 1.73 \mathrm{~m}^{2}$ versus eGFRcr_cys $>60 \mathrm{~mL} / \mathrm{min} / 1.73$ $\mathrm{m}^{2}$ ) (Table 3). CKD and non-CKD groups had significant differences when compared on the basis of triglycerides levels, serum creatinine, and cystatin C, eGFRcr_cys and also UACR. Diabetic patients with CKD had significant higher levels of IGF-1 and IGFBP-3 than diabetic patients without CKD (137.1 (85.0-165.1) ng/mL versus 98.00 (75.0-157.5) ng/mL, $P=0.04$, and 2467 (1700-3001) ng/mL versus 2198 (1753-3025) ng/mL, $P=0.0031$, respectively). Multivariate ANOVA revealed inverse associations of serum IGF-1 and IGFBP-3 with eGFR by using different cut-offs for eGFRcr_cys $(60,50,40$ and $30 \mathrm{~mL} / \mathrm{min} / 1.73$ $\mathrm{m}^{2}$, respectively) (Figure 1). However, according to multivariate analysis, only IGF-1 and cystatin C were

Table 1. Baseline characteristics of the study subjects

\begin{tabular}{|c|c|c|c|}
\hline Variables & $\begin{array}{c}\text { Diabetes } \\
n=102\end{array}$ & $\begin{array}{c}\text { Control } \\
n=68\end{array}$ & $P$ \\
\hline Age, years & $56.67 \pm 0.81$ & $48.20 \pm 8.10$ & 0.006 \\
\hline Duration of diabetes, years & $12.88 \pm 7.61$ & - & - \\
\hline $\mathrm{BMI}, \mathrm{kg} / \mathrm{m}^{2}$ & $34.03 \pm 12.08$ & $34.71 \pm 13.87$ & 0.761 \\
\hline Total cholesterol, $\mathrm{mmol} / \mathrm{L}$ & $5.36 \pm 1.36$ & $5.27 \pm 1.91$ & 0.244 \\
\hline LDL-cholesterol, mmol/L & $3.14 \pm 1.11$ & $3.18 \pm 0.99$ & 0.612 \\
\hline HS-CRP, mg/L & $4.49 \pm 7.68$ & $2.67 \pm 1.91$ & 0.441 \\
\hline $\mathrm{HbA1c}, \%$ & $7.82 \pm 1.69$ & $5.24 \pm 0.90$ & $<0.0001$ \\
\hline Systolic BP, mm Hg & $142.61 \pm 17.76$ & $125.44 \pm 17.46$ & $<0.0001$ \\
\hline Diastolic BP, mm Hg & $85.77 \pm 10.39$ & $80.18 \pm 10.53$ & 0.005 \\
\hline Triglycerides, mmol/L & $2.19 \pm 1.46$ & $1.57 \pm 1.96$ & 0.020 \\
\hline VLDL-cholesterol, $\mathrm{mmol} / \mathrm{L}$ & $0.99 \pm 0.67$ & $0.77 \pm 0.88$ & $<0.0001$ \\
\hline HDL-cholesterol, mmol/L & $1.24 \pm 0.37$ & $1.51 \pm 0.42$ & $<0.0001$ \\
\hline Creatinine, umol/L & $87.82 \pm 56.93$ & $69.10 \pm 14.18$ & 0.0001 \\
\hline Cystatin C, mg/L & $0.94 \pm 0.54$ & $0.81 \pm 0.22$ & $<0.0001$ \\
\hline eGFRcr_cys, $\mathrm{ml} / \mathrm{min} / 1.73 \mathrm{~m}^{2}$ & $76.78 \pm 25.41$ & $94.09 \pm 25.02$ & 0.0001 \\
\hline UACR, mg/g & $7.83 \pm 12.50$ & $4.46 \pm 6.34$ & 0.030 \\
\hline IGF-1, ng/mL & 98.6 (74.1-163.9) & $185.1(133-287)$ & 0.013 \\
\hline IGFBP-3, ng/mL & 2438 (1639-3004) & 2511 (1008-3099) & 0.999 \\
\hline
\end{tabular}

Values are mean \pm standard deviation or median (25th-75th percentile). 
Table 2. Univariate correlations between IGF-1, IGFBP-3 and other variables

\begin{tabular}{lcccc}
\hline & \multicolumn{2}{c}{ IGF-1 } & \multicolumn{2}{c}{ IGFBP-3 } \\
\cline { 2 - 5 } & $\boldsymbol{r}$ & $\boldsymbol{P}$ & $\boldsymbol{r}$ & $\boldsymbol{P}$ \\
\hline Age & -0.35 & 0.006 & -0.11 & 0.06 \\
Duration of diabetes & -0.19 & 0.15 & -0.14 & 0.16 \\
Body mass index & -0.13 & 0.33 & 0.04 & 0.70 \\
\hline Hemoglobin A1c & -0.11 & 0.41 & -0.01 & 0.99 \\
\hline Total cholesterol & 0.02 & 0.86 & -0.05 & 0.63 \\
Triglycerides & 0.11 & 0.39 & 0.17 & 0.08 \\
HDL-cholesterol & -0.03 & 0.8 & -0.14 & 0.76 \\
VLDL-cholesterol & 0.13 & 0.33 & 0.21 & 0.35 \\
Cystatin C & 0.61 & 0.0005 & 0.44 & 0.04 \\
Creatinine & 0.40 & 0.03 & 0.43 & 0.03 \\
eGFRcr_cys & -0.35 & 0.0042 & -0.46 & 0.04 \\
\hline
\end{tabular}

associated with renal impairment. In detail, the odds of having eGFR $<60 \mathrm{~mL} / \mathrm{min} / 1.73 \mathrm{~m}^{2}$ increased with rising IGF-1 levels (OR 1.025, [CI 1.002-1.048]) (Table 4).

\section{Discussion}

In the present study, we found an association between increased serum IGF-1, IGFBP- 3 and decreased eGFR in patients with diabetes. Elevated levels of IGF-1 and IGFBP-3 were associated with decreased GFR in patients with diabetes. The association remained significant only for IGF-1 after adjustment for age, duration of diabetes, HbA1c, hypertension, triglycerides and serum LDLcholesterol, in the logistic regression model. Our findings confirm the data from the NHANES III study (14) revealing a positive association between serum level of IGF-1 and the risk of CKD.

In contrast to our results, Frystyk et al showed lower free serum IGF-1 and higher serum IGFBP-3 concentrations in patients with $\mathrm{CKD}$ as compared to controls (15). At the same time, total IGF-1 concentrations were slightly but not
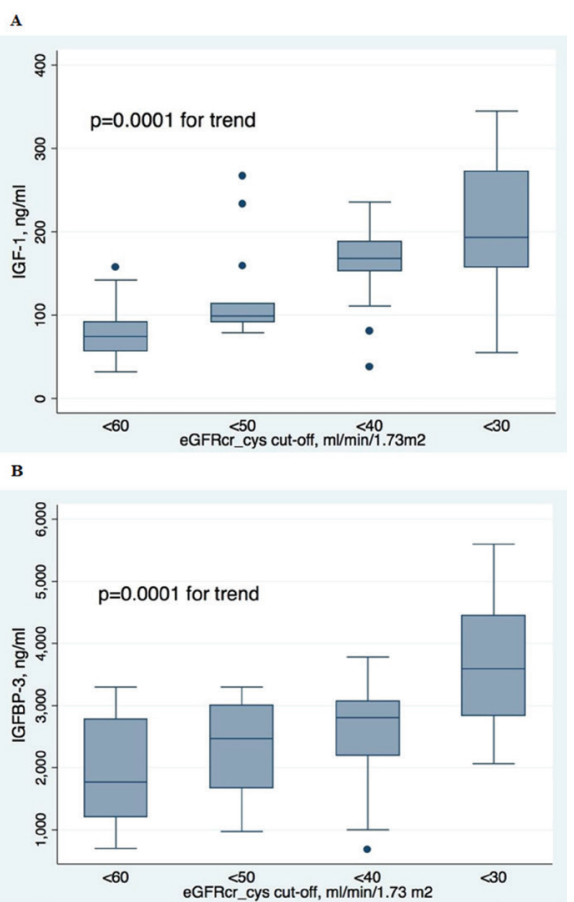

Figure 1. Median IGF-1 (A) and IGFBP-3 (B) levels in diabetic patients by different cut-offs for eGFRcr_cys.

significantly increased in individuals with CKD compared to healthy controls. In another study, hemodialysis patients had significantly higher serum levels of IGF-1 and IGFBP-3 than individuals without CKD (16). Normal serum IGF- 1 and elevated serum IGFBP- 3 concentrations have been shown in patients with CKD and different types of renal osteodystrophy as compared to healthy control subjects (17).

Previous studies have shown that IGF-1 is associated with cardiovascular disease, hypertension and diabetes, and since these conditions represent major risk factors for $\mathrm{CKD}$, it could be suggested that an increase in serum level

Table 3. Comparison of the clinical characteristics between CKD and non-CKD diabetic patients

\begin{tabular}{|c|c|c|c|}
\hline Variables & CKD diabetic patients $(n=62)$ & Non-CKD diabetic patients $(n=60)$ & $\boldsymbol{P}$ \\
\hline Age, years & $59.84 \pm 9.51$ & $60.04 \pm 8.23$ & 0.42 \\
\hline Systolic BP, mm Hg & $144.37 \pm 19.98$ & $141.65 \pm 17.77$ & 0.87 \\
\hline Diastolic BP, mm Hg & $86.57 \pm 8.34$ & $85.65 \pm 14.28$ & 0.68 \\
\hline Hemoglobin A1c, \% & $7.85 \pm 1.53$ & $7.76 \pm 1.62$ & 0.95 \\
\hline Total cholesterol, mmol/L & $5.27 \pm 0.89$ & $5.66 \pm 1.59$ & 0.24 \\
\hline Triglycerides, mmol/L & $2.09 \pm 1.71$ & $2.61 \pm 1.59$ & 0.02 \\
\hline LDL-cholesterol, $\mathrm{mmol} / \mathrm{L}$ & $3.11 \pm 0.81$ & $3.26 \pm 1.35$ & 0.61 \\
\hline Cystatin C, mg/L & $0.81 \pm 0.22$ & $0.94 \pm 0.54$ & $<0.0001$ \\
\hline Creatinine, umol/L & $74.18 \pm 14.11$ & $130.63 \pm 99.42$ & 0.0001 \\
\hline eGFRcr_cys, mL/min/1.73 m² & $85.03 \pm 19.07$ & $53.89 \pm 25.19$ & 0.0001 \\
\hline UACR, mg/g & $1.82 \pm 2.49$ & $11.23 \pm 15.43$ & 0.03 \\
\hline HS-CRP, mg/L & $3.39 \pm 1.72$ & $5.93 \pm 11.63$ & 0.83 \\
\hline IGF-1, ng/mL & $137.1(85.0-165.1)$ & $98.00(75.0-157.5)$ & 0.04 \\
\hline IGFBP-3, ng/mL & $2467(1700-3001)$ & $2198(1753-3025)$ & 0.003 \\
\hline
\end{tabular}

Values are mean \pm standard deviation or median (25th-75th percentile). 
Table 4. Logistic regression model for the presence of CKD

\begin{tabular}{lccc}
\hline CKD & OR & $95 \%$ Cl & $\boldsymbol{P}$ \\
\hline Age & 0.978 & $0.904-1.059$ & 0.586 \\
Duration & 0.984 & $0.881-1.098$ & 0.768 \\
SBP & 0.979 & $0.929-1.032$ & 0.439 \\
\hline IGF-1 & 1.025 & $1.002-1.048$ & 0.033 \\
\hline IGFBP-3 & 0.999 & $0.998-1.000$ & 0.192 \\
\hline HbA1C & 0.599 & $0.317-1.131$ & 0.114 \\
Cystatin C & 1.002 & $1.000-1.062$ & 0.001 \\
\hline Triglycerides & 0.523 & $0.191-1.435$ & 0.208 \\
\hline LDL-cholesterol & 1.677 & $0.619-4.547$ & 0.309 \\
\hline
\end{tabular}

$\mathrm{Cl}$, confidence interval; OR, odds ratio; SBP, systolic blood pressure.

of IGF-1 would be associated with development of CKD and thus might be a predictor of CKD.

It has been shown that both low and high IGF-1 serum concentrations are associated with an increased risk of mortality in the general population (18). In patients with mild or moderate renal impairment, serum IGF-1 concentrations may be elevated due to increased IGF-1 half-life and may become clinically relevant in patients with severe or end-stage CKD. However, we did not measure free IGF-1 which would provide a more accurate view on the association between GH- IGF axis and renal function in patients with diabetes. It could also be argued that there is no more risk on top of diabetes risk and probably IGF-1 is not specific for impaired renal function in patients with diabetes.

Most studies (19-21) evaluating the interconnections between the GH-IGF axis and lipid metabolism included patients with pituitary diseases. In detail, patients with GH deficiency demonstrated higher triglyceride levels, while HDL levels were lower as compared to healthy controls. Interestingly, GH replacement therapy led to an improvement in lipid profile by increasing HDL, as well as decreasing total cholesterol, LDL-cholesterol and triglyceride levels in GH deficient patients $(22,23)$. In contrast to the above data, population-based studies (24, $25)$ yielded conflicting results regarding the associations of IGF-1 or IGFBP-3 levels with parameters of lipid metabolism. Filipsson Nyström et al (26) found an inverse relationship between IGF-1 and cholesterol levels in 202 individuals. The currently largest population-based study with 3977 subjects showed similar results demonstrating inverse associations between IGF-1 and total or HDL cholesterol, as well as positive relationships of IGFBP-3 levels with HDL-C and triglycerides (27). Thus, a positive association between IGFBP-3 and triglycerides detected in our study is consistent with the results of other studies. However, additional investigations have to be done to further explain the link between IGF-1 axis and triglycerides.

\section{Conclusion}

In conclusion, our study revealed that higher serum IGF1 levels were positively associated with CKD in patients with DM. Thus, the odds of having eGFR $<60 \mathrm{~mL} /$ $\mathrm{min} / 1.73 \mathrm{~m}^{2}$ increased with rising IGF-1 levels (OR 1.025, [CI 1.002-1.048]). Our results suggest that IGF-1 might be a predictor of CKD in patients with diabetes. Further studies are necessary to confirm the observed association and to detect the causal relations.

\section{Limitations of the study}

Our study had several limitations. First, this study was limited by the relatively small sample size. In addition, a restricted number of variables were analyzed. Inclusion of other potential confounders, such as IGFBP-1, free IGF1 and IGF-2, could have an impact on the conclusions. Future studies investigating all these parameters together are needed. Furthermore, we did not evaluate new markers of impaired renal function or injury and used a single cystatin $\mathrm{C}$ assay. However, it has been shown that the use of serum cystatin C-based GFR is more accurate for early diagnosis of CKD. Additionally, retrieval of data on potential confounders such as concomitant medication and smoking status was not possible. Further studies are needed to clarify the prognostic value of serum IGF-1 level in patients with DM.

\section{Authors' contribution}

VKB and EPN searched the data and prepared the draft of the manuscript. EPN, LEK and NAF collected the data and did much of the analysis. TVM made some critical comments on the manuscript. VNV, IYP and TVM conducted the final check, final editing and finalized the paper. All authors read and signed the final manuscript.

\section{Conflicts of interest}

All authors declare that they do not have a conflict of interest with the contents of this paper.

\section{Ethical considerations}

Ethical issues (including plagiarism, data fabrication, double publication) have been completely observed by the authors.

\section{Funding/Support}

This study was supported by the Belarusian Foundation for Basic Research (BFBR) according to the research project No. M17PM-113 (01.06.2017) and Russian Foundation for Basic Research (RFBR) according to the research project No.17-54-04080.

\section{References}

1. Go AS, Chertow GM, Fan D, McCulloch CE, Hsu CY. Chronic kidney disease and the risks of death, cardiovascular events, and hospitalization. N Engl J Med. 2004;351:1296305. doi: 10.1056/NEJMoa041031 
2. Klag MJ, Whelton PK, Randall BL, Neaton JD, Brancati FL, Stamler J. End-stage renal disease in African-American and white men: 16-year MRFIT findings. JAMA. 1997;277:1293-8.

3. Bibbins-Domingo K, Chertow GM, Fried LF, Odden MC, Newman AB, Kritchevsky SB, et al. Renal function and heart failure risk in older black and white individuals: The Health, Aging, and Body Composition Study. Arch Intern Med. 2006;166:1396-402. doi: 10.1001/archinte.166.13.1396

4. American Diabetes Association. Microvascular complications and foot care: standards of medical care in diabetes - 2019. Diabetes Care. 2019;42:124-38. doi: 10.2337/dc19-S011.

5. Coll E, Botey A, Alvarez L, Poch E, Quinto L, Saurina A, et al. Serum cystatin $\mathrm{C}$ as a new marker for noninvasive estimation of glomerular filtration rate and as a marker for early renal impairment. Am J Kidney Dis. 2000;36:29-34. doi: 10.1053/ ajkd.2000.8237

6. Dharnidharka VR, Kwon C, Stevens G. Serum cystatin C is superior to serum creatinine as a marker of kidney function: a meta-analysis. Am J Kidney Dis. 2002;40:221-6. doi: 10.1053/ajkd.2002.34487

7. Hojs R, Bevc S, Antolinc B, Gorenjak M, Puklavec L. Serum cystatin $\mathrm{C}$ as an endogenous marker of renal function in the elderly. Int J Clin Pharm. 2004;24:49-54.

8. Waikar SS, Betensky RA, Bonventre JV. Creatinine as the gold standard for kidney injury biomarker studies? Nephrol Dial Transplant. 2009;24:3263-5. doi: 10.1093/ndt/gfp428

9. Bjornsson TD. Use of serum creatinine concentrations to determine renal function. Clin Pharmacokinet. 1979; 4:20022. doi: 10.2165/00003088-197904030-00003.

10. Kamenicky P, Mazziotti G, Lombes M, Giustina A, Chanson P. Growth hormone, insulin-like growth factor-1, and the kidney: pathophysiological and clinical implications. Endocr Rev. 2014;35:234-81. doi: 10.1210/er.2013-1071.

11. Fujihara M, Uemasu J, Kawasaki H. Serum and urinary levels of insulin-like growth factor I in patients with chronic renal disease and diabetes mellitus: its clinical implication. Clin Nephrol. 1996;45:372-8.

12. Atamer A, Alisir Ecder S, Akkus Z, Kocyigit Y, Atamer Y, Ilhan N, Ecder T. Relationship between leptin, insulin resistance, insulin-like growth factor-1 and insulinlike growth factor binding protein-3 in patients with chronic kidney disease. J Int Med Res. 2208;36:522-8. doi: 10.1177/147323000803600317

13. Inker LA, Eckfeldt J, Levey AS, Leiendecker-Foster C, Rynders G, Manzi J et al. Expressing the CKD-EPI (Chronic Kidney Disease Epidemiology Collaboration) cystatin C equations for estimating GFR with standardized serum cystatin C values. Am J Kidney Dis. 2011;58:682-4. doi: 10.1053/j.ajkd.2011.05.019.

14. Sierra-Johnson J, Romero-Corral A, Somers VK, LopezJimenez F, Mälarstig A, Brismar K, et al. IGF-I/IGFBP-3 ratio: a mechanistic insight into the metabolic syndrome. Clin Sci. 2009;116:507-12. doi: 10.1042/CS20080382

15. Frystyk J, Ivarsen P, Skjaerbaek C, Flyvbjerg A, Pedersen EB, Orskov H. Serum-free insulin-like growth factor I correlates with clearance in patients with chronic renal failure. Kidney Int. 1999;56:2076-84. doi: 10.1046/j.1523-1755.1999.00798.x. 16. Iglesias P, Díez JJ, Fernández-Reyes MJ, Méndez J, Bajo
MA, Aguilera A, Selgas R. Growth hormone, IGF-I and its binding proteins (IGFBP-1 and -3) in adult uremic patients undergoing peritoneal dialysis and hemodialysis. Clin Endocrinol (Oxf). 2004; 60:741-9. doi: 10.1111/j.13652265.2004.02049.x.

17. Jehle PM, Ostertag A, Schulten K, Schulz W, Jehle DR, Stracke $\mathrm{S}$, et al. Insulin-like growth factor system components in hyperparathyroidism and renal osteodystrophy. Kidney Int. 2000;57:423-36. doi: 10.1046/j.1523-1755.2000.00862.x.

18. Burgers AM, Biermasz NR, Schoones JW, Pereira AM, Renehan AG, Zwahlen M, et al. Meta-analysis and doseresponse metaregression: circulating insulin-like growth factor I (IGF-I) and mortality. J Clin Endocrinol Metab. 2011;96:2912-20. doi: 10.1210/jc.2011-1377.

19. de Boer H, Blok GL, Voerman HJ, Phillips M, Schouten JA. Serum lipid levels in growth hormone-deficient men. Metabolism. 1994;43:199-203. doi: 10.1016/00260495(94)90245-3.

20. Rosen T, Eden S, Larson G, Wilhelmsen L, Bengtsson BA. Cardiovascular risk factors in adult patients with growth hormone deficiency. Acta Endocrinol. 1993;129:195-200. doi: $10.1530 /$ acta.0.1290195.

21. Abs R, Feldt-Rasmussen U, Mattsson AF, Monson JP, Bengtsson BA, Goth MI, et al. Determinants of cardiovascular risk in 2589 hypopituitary GH-deficient adults - a KIMS database analysis. Eur J Endocrinol. 2006;155:79-90. doi: 10.1530/eje.1.02179.

22. Colao A, di Somma C, Cuocolo A, Spinelli L, Tedesco N, Pivonello R, et al, Improved cardiovascular risk factors and cardiac performance after 12 months of growth hormone (GH) replacement in young adult patients with GH deficiency. J Clin Endocrinol Metab. 2001;86:1874-81. doi: 10.1210/jcem.86.5.7464.

23. Fideleff HL, Jonsson B, Koltowska-Haggstrom M, Boguszewski MC, Wilton P, Boquete HR. GH deficiency during the transition period: clinical characteristics before and after GH replacement therapy in two different subgroups of patients. J Pediatr Endocrinol Metab. 2012;25:97-105. doi: 10.1515/jpem.2011.349.

24. Kim ES, Park JH, Lee MK, Lee DH, Kang ES, Lee HC, et al. Associations between fatness, fitness, IGF and IMT among obese Korean male adolescents. Diabetes Metab. 2011;35:610-18. doi: 10.4093/dmj.2011.35.6.610.

25. Ceda GP, Dall'Aglio E, Magnacavallo A, Vargas N, Fontana $\mathrm{V}$, Maggio M, et al. The insulin-like growth factor axis and plasma lipid levels in the elderly. J Clin Endocrinol Metab. 1998;83:499-502. doi: 10.1210/jcem.83.2.4548.

26. Filipsson Nyström H, Barbosa EJ, Nilsson AG, Norrman LL, Ragnarsson O, Johannsson G. Discontinuing long-term GH replacement therapy - a randomized, placebo-controlled crossover trial in adult GH deficiency. J Clin Endocrinol Metab. 2012;97:3185-95. doi: 10.1210/jc.2012-2006.

27. Lam CS, Chen MH, Lacey SM, Yang Q, Sullivan LM, Xanthakis V, et al. Circulating insulin-like growth factor-1 and its binding protein-3: metabolic and genetic correlates in the community. Arterioscler Thromb Vasc Biol. 2010;30:1479-84. doi: 10.1161/ATVBAHA.110.203943.

Copyright (C) 2021 The Author(s); Published by Nickan Research Institute. This is an open-access article distributed under the terms of the Creative Commons Attribution License (http://creativecommons.org/licenses/by/4.0), which permits unrestricted use, distribution, and reproduction in any medium, provided the original work is properly cited. 